\title{
BIOCHEMICAL OBSERVATIONS ON THE USE OF L-GLUTAMIC ACID IN THE TREATMENT OF HEPATIC COMA
}

\author{
By FRANK L. IBER ${ }^{2}$ AND THOMAS C. CHALMERS ${ }^{2}$ WITH THE TECHNICAL ASSISTANCE \\ oF BARBARA STOWERS, ALBERT FRYAR, AND ANNA MARIE LINK \\ (From the Department of Metabolism, Division of Medicine, Walter Reed Army Institute of \\ Research, Walter Reed Army Medical Center, Washington, D. C.)
}

(Submitted for publication October 4, 1956; accepted January 17, 1957)

The neurological pattern of hepatic coma has been characterized by Adams and Foley (1), and their observations facilitate the early recognition of this syndrome. A similar syndrome has been produced by the administration of certain nitrogenous substances (2) or a high protein diet (3) and has been observed following portacaval shunt (4) or total hepatectomy (5). Blood ammonia levels in hepatic coma are usually elevated, but there is poor correlation with the neurological state. Walshe (6) reported in 1953 the successful treatment of hepatic coma with large amounts of 1-glutamic acid. Although beneficial results have been reported with glutamic acid by some investigators $(7-11)$, in contrast, no benefit has been observed from this treatment by others (12-14). However, independent of the clinical result the blood ammonia decreases with glutamic acid therapy $(7,12,14)$.

Walshe (6) proposed that an excess of intracellular ammonia accumulates in the brain in hepatic coma because of disturbed metabolism of glutamic acid. The administration of glutamic acid might correct this defect. Bessman and Bessman (15) believed that interference with energy metabolism in the brain by removal of alphaketoglutarate is the essential lesion of hepatic coma. The present study characterizes some of the biochemical changes in the serum accompanying the fall in blood ammonia produced by the infusion of sodium glutamate in normal persons and patients in hepatic coma.

\section{CLINICAL PROCEDURES AND METHODS}

Glutamic acid infusions were given to two normal subjects and eight patients with cirrhosis. All were studied on the wards of the Walter Reed Army hospital.

\footnotetext{
${ }^{1}$ Formerly Captain, MC, USAR. Present address: Johns Hopkins Hospital, Baltimore, Maryland.

2 Formerly Captain, MC, USAR. Present address : Lemuel Shattuck Hospital, Boston, Massachusetts.
}

The diagnosis of pre-coma was made in such cases by serial observations of developing stupor, confusion, and flapping tremor in patients with chronic liver disease. The criteria for the definition of coma are those outlined by Webster and Davidson (13). All patients were fasting during the time of study and glucose was administered at a constant rate as far as possible. None of the patients was in shock, but patients 8,9 , and 4 during Study "C" received blood transfusion during the aftercontrol period because of continued gastrointestinal hemorrhage. Azotemia was not observed but oliguria was present in all coma patients. Pertinent clinical information for each subject is given in Table $I$.

Blood ammonia was determined on fresh heparinized venous blood. All determinations were made in triplicate using a microdiffusion method $(16,17)$. The average deviation of replicates on the same blood sample from the mean (18) was $7.6 \pm 3.1 \mu \mathrm{M}$ per L. ${ }^{3}$ Simultaneous arterial and venous blood samples were obtained from five patients and analyzed for ammonia and alpha-ketoglutarate. The arterial blood ammonia was always higher than the venous blood ammonia, suggesting extraction of ammonia by the musculature as reported by Bessman and Bradley (19), but the alpha-ketoglutarate did not change. The impression was gained during the collection of samples that the brighter venous bloods had higher ammonia values. For this reason, the effects of in vitro oxygenation on the blood ammonia were studied. Venous blood was equilibrated in a tonometer with a stream of washed oxygen or nitrogen, and at the end of five minutes the original unagitated venous blood and both treated samples were analyzed for ammonia. The nitrogen equilibration was employed as a control, for the gassing process caused the loss of some ammonia. All determinations were performed in triplicate and the sequence of analysis was varied so that the oxygenated sometimes preceded and sometimes followed the other analyses. Actual ammonia analyses were started within 20 minutes of shedding of the blood and the first and last samples were invariably less than five minutes apart. The oxygenated blood assumed a bright red color in contrast to both the control venous and the nitrogenated blood; however, the oxygen tension was not directly measured. Blood from six normal persons and from four patients with cirrhosis was treated in this manner.

8 The designation $\mu \mathrm{M}$ per $\mathrm{L}$. is used for all substances to facilitate comparisons. One $\mu \mathrm{M}$ per $\mathrm{L}$. of ammonia is equivalent to $0.017 \gamma$ per $\mathrm{ml}$. 
TABLE I

Pertinent clinical information on the normal subjects and patients with cirrhosis

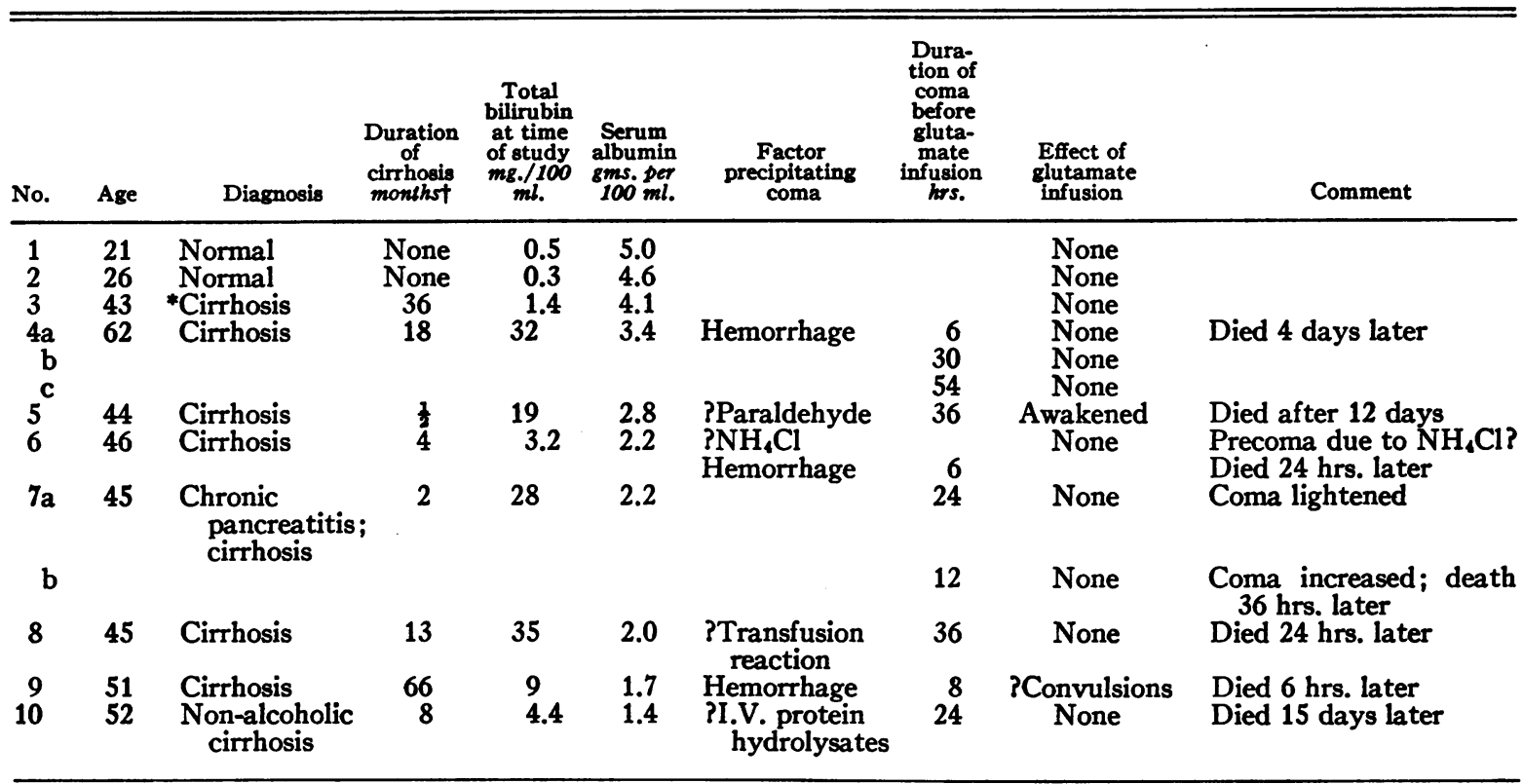

* No signs of coma.

† Dated from the time of the first clinical diagnosis or unequivocal historical sign of decompensation.

None of the patients is one of those described in this paper, for this phenomenon was not investigated at that time. The results are recorded in Table II. The blood saturated with oxygen from both the normal and cirrhotic patients had a higher ammonia value than blood saturated with nitrogen, and the control value was generally intermediate. The interpretation of arterial-venous ammonia differences remains difficult until the in vitro effects of oxygenation, recently confirmed (20), are further clarified.

Glutamine was measured by the procedure of Iber and Bruton (21), employing an enzyme prepared from the kidneys of acidotic rats. Pyruvic acid and alpha-ketoglutarate were measured by the method of Seligson, McCormick, and Sborov (22). Citric acid was measured by the method of Ettinger, Goldbaum, and Smith (23). Amino acids were measured by column chromatography using the technique of Moore and Stein (24). A portion of the glutamine is hydrolyzed on the column in this method and appears as glutamic acid.

Monosodium glutamate was infused into two normal persons and eight patients with cirrhosis. All patients received intravenous glucose before and after study. Monosodium glutamate (approx. $24 \mathrm{gm}$.) was prepared in $500 \mathrm{cc}$. of $\mathbf{5}$ per cent glucose; the rate of infusion was adjusted so that glucose was given at the same rate before, during, and after the glutamate infusion. The time, amount, and duration of the glutamate infusion are given

- These determinations were obtained through the cooperation of Dr. Stanley Levenson and Mr. Hyman Rosen. in Table III. Blood samples were taken in aqueous heparin and processed immediately for analysis. The samples for citric acid, pyruvic acid, alpha-ketoglutaric acid, glutamine, and amino acids were stored frozen until analyzed.

\section{Blood "ammonia"}

RESULTS

The blood "ammonia" was elevated prior to therapy in the patients in coma (average value, $215 \mu \mathrm{M}$ per L.; normals, 67.6) (Table III), but

TABLE II

The effects of oxygen tension on blood "ammonia" (gamma per ml.)*

Normals

\begin{tabular}{llllllr}
\hline Oxygenation & 1.51 & 1.19 & 1.33 & 1.16 & 1.35 & 1.14 \\
Control Venous & 1.21 & 0.90 & 1.66 & 1.19 & 1.35 & 1.01 \\
Nitrogenation & 1.16 & 0.70 & 1.12 & 0.73 & 1.07 & 1.21 \\
$\mathrm{O}_{2}-\mathrm{N}_{2}$ Difference & $\mathbf{0 . 3 5}$ & 0.49 & $\mathbf{0 . 2 1}$ & $\mathbf{0 . 4 3}$ & $\mathbf{0 . 2 8}$ & $\mathbf{- 0 . 0 7}$ \\
\hline
\end{tabular}

Cirrhotics

\begin{tabular}{lllll}
\hline Oxygenation & 1.03 & 2.08 & 1.42 & 1.67 \\
Control Venous & 1.13 & 1.89 & 1.29 & 1.31 \\
Nitrogenation & 0.91 & 1.54 & 1.31 & 1.23 \\
$\mathrm{O}_{2}-\mathrm{N}_{2}$ Difference & 0.12 & $\mathbf{0 . 5 4}$ & $\mathbf{0 . 1 1}$ & $\mathbf{0 . 4 4}$
\end{tabular}

* Mean difference of oxygenation-nitrogenation is $0.29 / \mathrm{ml}$

S.E. of difference is $0.062 \mathrm{P}<.01$. 
TABLE III

Changes in blood levels before and after intravenous sodium glutamate

\begin{tabular}{|c|c|c|c|c|c|c|c|c|c|c|c|c|c|c|}
\hline \multirow[b]{2}{*}{ No. } & \multirow{2}{*}{$\begin{array}{c}\text { Dose of } \\
\text { glutamate } \\
\text { and } \\
\text { duration }\end{array}$} & \multirow{2}{*}{$\begin{array}{c}\text { Control and } \\
\text { duration }\end{array}$} & \multicolumn{2}{|c|}{$\underset{\mu M . / L}{\text { Ammonia }}$} & \multicolumn{2}{|c|}{ 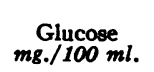 } & \multicolumn{2}{|c|}{$\begin{array}{l}\text { Alpha-keto- } \\
\text { glutarate } \\
\mu M . / L .\end{array}$} & \multicolumn{2}{|c|}{$\begin{array}{l}\text { Pyruvate } \\
\mu M . / L \text {. }\end{array}$} & \multicolumn{2}{|c|}{$\begin{array}{l}\text { Citrate } \\
\mu M . / L .\end{array}$} & \multicolumn{2}{|c|}{$\begin{array}{l}\text { Glutamine } \\
\mu M . / L .\end{array}$} \\
\hline & & & Before & After & Before & After & Before & After & Before & After & Before & After & Before & After \\
\hline \multicolumn{2}{|c|}{ Normal values* } & & \multicolumn{2}{|c|}{$67.6 \pm 10$} & & & \multicolumn{2}{|c|}{$13.0 \pm 1.5$} & \multicolumn{2}{|c|}{$73 \pm 16$} & \multicolumn{2}{|c|}{79.2} & \multicolumn{2}{|c|}{$550-760$} \\
\hline $1 \dagger$ & $\begin{array}{c}24 \mathrm{gm} . \\
3 \frac{1}{8} \mathrm{hrs} .\end{array}$ & $\begin{array}{l}\text { Glucose } \\
2 \mathrm{hrs} .\end{array}$ & 166 & 72 & 88 & 96 & 12.4 & 20.6 & & 128 & 70 & 58 & 229 & 265 \\
\hline $2 \dagger$ & $\begin{array}{l}22 \mathrm{gm} . \\
3 \frac{1}{8} \mathrm{hrs} .\end{array}$ & $\begin{array}{l}\text { Glucose } \\
1 \frac{1}{\mathrm{~h}} \mathrm{hrs} .\end{array}$ & & & 77 & 82 & 11.3 & 17.8 & 69 & 71 & & & & \\
\hline $3 \ddagger$ & $24 \mathrm{gm}$. & $\begin{array}{l}\text { Glucose } \\
21 \mathrm{hrs} .\end{array}$ & 204 & 161 & & & 15.6 & 21.5 & 68.5 & 59.6 & 84.3 & 90.6 & & \\
\hline $4 a$ & $\begin{array}{l}24 \mathrm{gm} . \\
2 \frac{1}{2} \mathrm{hrs} .\end{array}$ & & 140 & 88 & 90 & 123 & 29.7 & 144.5 & 156 & 260 & 73.4 & 122 & 700 & 1,240 \\
\hline b & $\begin{array}{l}24 \mathrm{gm} . \\
4 \frac{7}{3} \mathrm{hrs} .\end{array}$ & & 138 & 107 & & & & & & & & & & \\
\hline c & $20 \mathrm{gm}$. & $\begin{array}{c}\text { Glucose } \\
2 \text { hrs. }\end{array}$ & 176 & 126 & & & & & & & & & 516 & 410 \\
\hline 5 & $\begin{array}{l}32 \mathrm{gm} . \\
4.5 \mathrm{hrs} .\end{array}$ & & 148 & 76 & & & 53.3 & 76.5 & 224.4 & 106.1 & 127 & 114 & & \\
\hline 6 & $\begin{array}{l}20 \mathrm{gm} . \\
5.5 \mathrm{hrs} .\end{array}$ & $\begin{array}{c}\text { Glucose } \\
2 \text { hrs. }\end{array}$ & 370 & 122 & 53 & 65 & 36.8 & 57.5 & 355 & 468 & 368 & 290 & & \\
\hline $7 a$ & $\begin{array}{l}18 \mathrm{gm} . \\
6 \frac{3}{4} \mathrm{hrs} .\end{array}$ & & 165 & 103 & 124 & 212 & 33.2 & 47.5 & 56 & 103 & 201 & 223 & & \\
\hline b & $\begin{aligned} 24 & \text { gr. } \\
3 & \text { hrs. }\end{aligned}$ & $\begin{array}{l}\text { Ca gluconate } \\
2 \text { hrs. }\end{array}$ & 248 & 149 & 114 & 107 & 65.1 & 83.0 & 326 & 259 & 130 & 102 & 1,510 & 1,580 \\
\hline 8 & $\begin{array}{r}24 \text { gm. } \\
3 \text { hrs. }\end{array}$ & & 2,440 & 3,550 & 90 & 69 & 36.2 & 117 & 506 & 387 & 154 & 198 & 1,630 & 1,610 \\
\hline 9 & $\begin{array}{l}40 \text { gm. } \\
3 \text { hrs. }\end{array}$ & $\begin{array}{c}\text { Glucose } \\
3 \text { hrs. }\end{array}$ & 421 & 254 & 133 & 160 & 83.0 & 60.3 & 517 & 433 & 103 & 108 & & \\
\hline 10 & $20 \mathrm{gm}$. & $\begin{array}{c}\text { Glucose } \\
2 \text { hrs. }\end{array}$ & 191 & 158 & 208 & 178 & 23.7 & 18.8 & 123 & 108 & & & 925 & 990 \\
\hline
\end{tabular}

* From the authors' laboratory. Glutamine range based on ten normals (21), mean citrate value taken from Ettinger, Goldbaum, and Smith (23). Pyruvate and alpha-ketoglutarate based on 17 normal subjects and the ammonia on 25 normal subjects.

+ "Normal" patients.

$\ddagger$ Patient with cirrhosis and no signs of coma.

the degree of elevation did not correlate with the depth of the coma. The levels tended to rise during the control infusions of glucose. In patient

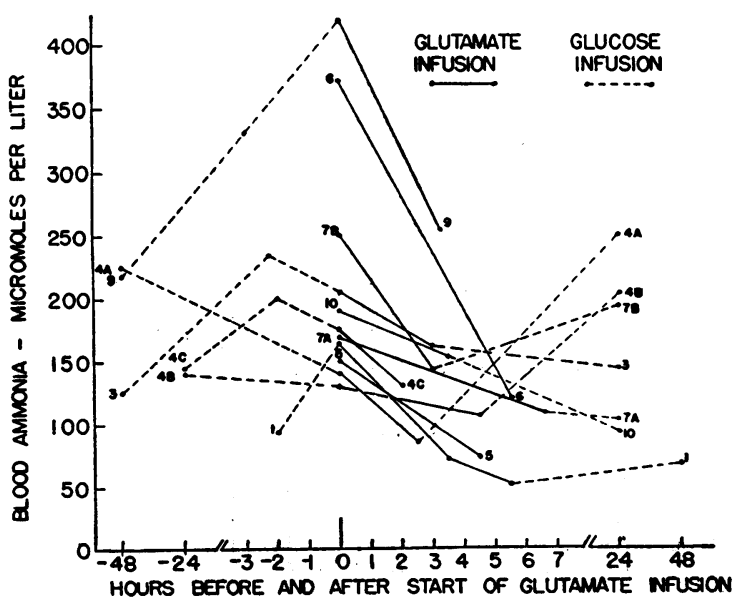

Fig. 1. The Efrect of Glutamate Infusion on the Concentration of Blood "Ammonia"

The numbers identify the patients in Tables I and III.
8 extremely high levels of ammonia were found, $2,440 \mu \mathrm{M}$ per $\mathrm{L}$. initially, and values of similar magnitude were found in three subsequent blood specimens. The patient died a few hours after these observations. Review of the clinical information led subsequently to the suspicion that this man had septicemia with a urea splitting organism, but no blood culture was taken while the patient was alive and review of the pathology sections for bacteria did not support this possibility. The ammonia values of this case are excluded from the averages and from the figures in this paper. Sodium glutamate was effective in lowering the blood ammonia in all other patients (Figure 1). The lowering of the blood ammonia was on the average $87 \mu \mathrm{M}$ per L. or 40 per cent of the initial value. The degree of lowering was not related in a simple fashion to either the dose given or the rate at which it was given within the ranges employed. There was no relationship between the amount of lowering and the clinical changes in 
the patient. Most of the ammonia values 24 hours after treatment had returned to pre-treatment levels.

\section{Alpha-ketoglutarate}

Blood alpha-ketoglutarate levels prior to the glutamic acid infusion were elevated from two to six times the normal level in the patients with liver coma. In four patients there was no striking change during the control infusions of glucose. In eight of ten infusions of glutamic acid there was a rise in ketoglutarate by from one-quarter to five times the initial value (Figure 2); in patients 9 and 10 there was a 25 per cent fall, possibly associated with a greater interval between cessation of the infusion and withdrawal of the specimen. In the study of patient 2 , a normal subject, samples of blood were taken five minutes before the completion of the glutamic acid infusion, five minutes, 15 minutes, and 60 minutes after the completion. These data are presented in Table IV and Figure 3. The alpha-ketoglutarate level rises by 57 per cent and returns to the starting level within 15 minutes of the end of the infusion. The rapid changes in the levels of glutamic acid, alanine, and the glutamine-asparagine-serine complex are also to be noted.

\section{Pyruvate, citrate, and glutamine}

Blood pyruvate concentrations were elevated to two to seven times the normal in seven of

TABLE IV

Effect of sodium glutamate infusion on plasma substances *

\begin{tabular}{lccccc}
\hline & $\begin{array}{c}\text { Start of } \\
\text { infusion }\end{array}$ & $\begin{array}{c}5 \text { Min. } \\
\text { before } \\
\text { end }\end{array}$ & $\begin{array}{c}5 \text { Min. } \\
\text { after } \\
\text { end }\end{array}$ & $\begin{array}{c}15 \text { Min. } \\
\text { after } \\
\text { end }\end{array}$ & $\begin{array}{c}60 \text { Min. } \\
\text { after } \\
\text { end }\end{array}$ \\
\hline $\begin{array}{l}\text { Threonine } \\
\text { Glutamine, }\end{array}$ & 79 & 78 & 73 & 76 & \\
$\begin{array}{l}\text { asparagine, } \\
\text { serine f. }\end{array}$ & 168 & 210 & 215 & 87 & \\
$\begin{array}{l}\text { Glutamic acid } \\
\text { Glycine }\end{array}$ & 112 & 1130 & 775 & 400 & \\
Alanine & 200 & 305 & 235 & 182 & \\
Ketoglutarate & 11.3 & 17.8 & 16.0 & 11.8 & 13.6 \\
$\begin{array}{l}\text { Pyruvate } \\
\text { Citrate }\end{array}$ & 69.1 & 71.0 & 67.5 & 78.8 & 70.2 \\
Glucose & 80 & 110 & 127 & 109 & 193 \\
\hline
\end{tabular}

* Twenty-four gm. Na glutamate given over 205 minutes to a normal subject. Glucose given at uniform rate throughout the study.

$\dagger$ These came off as a group on the ion-exchange column. There may be loss of glutamine.

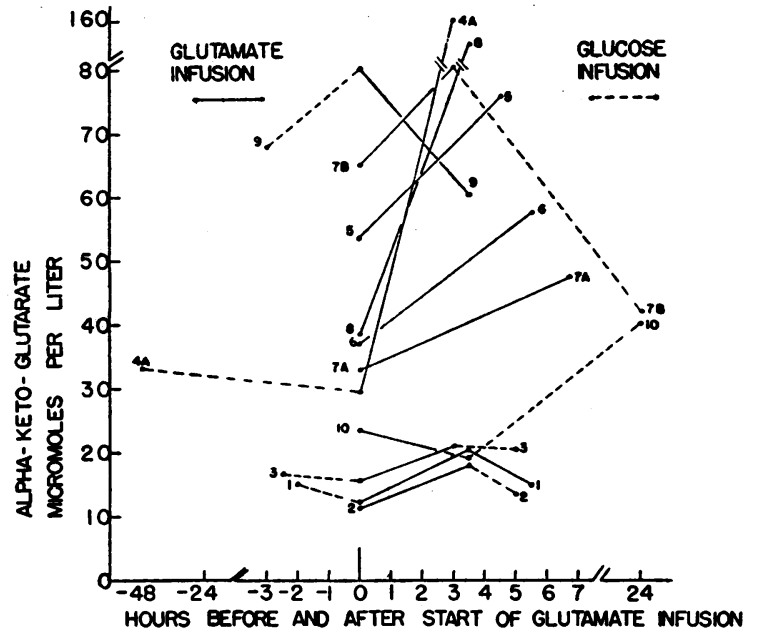

Fig. 2. The Effect of Glutamate Infusion on the Concentration of Alpha-Ketoglutarate

The numbers identify the patients in Tables I and III.

eight of the comatose patients. Citrate concentration was elevated in six out of seven instances. The changes produced by glutamate infusion were variable. Glutamine was determined before and after six of the glutamate infusions. Although there was a rise in glutamine in four of the six infusions, only three of these showed a rise equal in concentration to the fall in ammonia. The

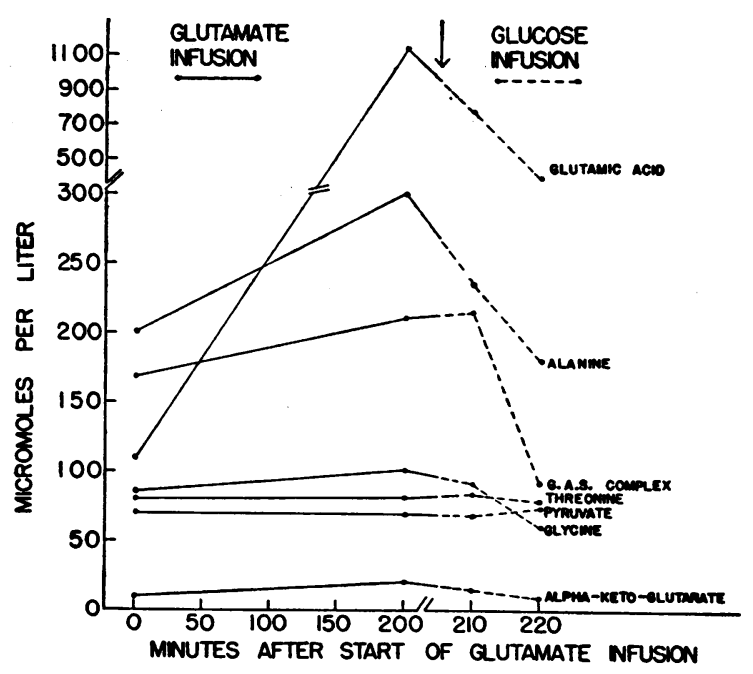

Fig. 3. Changes in the Concentrations of Related Metabolites with Tme After Cessation of Glutamate InFusion

Note the expansion of time scale after the cessation of glutamate. A 50 per cent rise and fall of ketoglutarate are minimized by the scale. 
overall average change in glutamine was an increase of $96 \mu \mathrm{M}$ per L. However, if case $4 \mathrm{a}$ is excluded there is essentially no change.

\section{Clinical observations}

One normal subject and the cirrhotic patient without coma tolerated the infusion well. The other normal subject had nausea, but no vomiting or other symptoms. Patient 5 is the only comatose patient who awakened with the infusion, and he remained alert for several days. The depth of coma seemed to lessen in patient 7 at the time of the first infusion but two days later the depth of coma increased during a second infusion. $\mathrm{He}$ died soon thereafter in coma. Patient 6 had a spontaneous remission from coma. Three days later coma recurred, and glutamic acid was given but did not produce a remission.

\section{DISCUSSION}

Glutamic acid as employed in this study was of little value in the treatment of the clinical manifestations of hepatic coma. These observations confirm the experience of others $(13,14)$ who found only transient beneficial effects. It must be pointed out that our group of patients all had chronic liver disease underlying their coma, and that this group is most refractory to glutamic acid treatment (7). Coma precipitated by exogenous factors such as gastrointestinal hemorrhage or ammonium chloride has been said to respond more consistently (10), but no support for this could be found in the present study. The dose of sodium glutamate, approximately $24 \mathrm{gm}$., is a smaller dose than that recommended by Walshe (7).

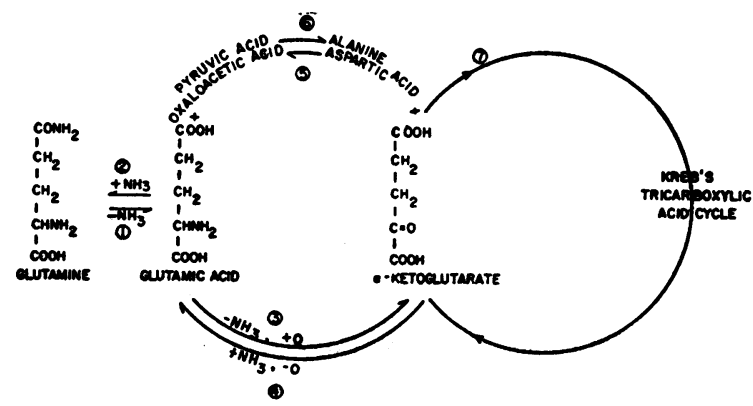

Fig. 4. Schematic Interrelations of Metabolites Arranged to Suggest Various Mechanisms by Which Glutamate may Lower the Blood "Ammonia" ConCENTRATION
Before the biochemical changes are discussed two limitations of this study must be stated. All measurements were made on the blood, which reflects only gross changes in the body. The changes to be described for various metabolites probably occur at the intracellular level or in fluid compartments not in immediate equilibrium with the plasma. In addition, the data shown in Table IV and Figure 3 suggest that rapid changes in the blood levels at the time of cessation of the infusion may cause an appreciable variability in the data obtained from the rest of the patients.

The blood ammonia was lowered by glutamic acid in all except patient 8 . Thus glutamic acid offers an effective method for lowering the blood ammonia. The possible reactions that could account for the disappearance of these quantities of blood "ammonia" (average $87 \mu \mathrm{M}$ per L.) are outlined in Figure 4. The only direct reaction between glutamic acid and ammonia is No. 2, in which ammonia is added to glutamic acid to yield glutamine. Foster, Schoenheimer, and Rittenberg (25) have observed that the disappearance of isotopically labelled $\mathrm{NH}_{3}$ in the normal rat is accompanied by the rapid accumulation of radioactivity in amide nitrogen, presumably glutamine. The possible value of this reaction for the removal of ammonia initially led Walshe to infuse glutamic acid (6). Glutamine rose in four of the six cases in which it was measured but in only three was the magnitude sufficient to account for the fall in ammonia. Since glutamine is not known to transfer the ammonia to other substances, its accumulation might be expected. Conversions of glutamate to glutamine cannot be the sole mechanism for ammonia removal because the glutamine actually fell in cases $4 c$ and 8 and rose inadequately in cases 1 and $7 \mathrm{~b}$. Bessman (26) believes that this reasoning is incorrect because the kidney deaminates glutamine so rapidly that it cannot accumulate in the blood. However, a lack of increase in glutamine after glutamic acid administration was also demonstrated by Walshe (7) and Singh, Barclay, and Cooke (12).

The route of removal of infused glutamic acid is unknown. The dose used in this study (24 gm.) would represent $2,300 \mu \mathrm{M}$ per $\mathrm{L}$. in 55 liters, the approximate total body water of patient 2 , a man weighing $82 \mathrm{~kg}$. At the end of the infusion the maximum level of glutamic acid was $1,130 \mu \mathrm{M}$ 
per L. and the level fell to less than half of this value 15 minutes after cessation of the infusion (Table IV, Figure 3). At no time were there rises in the glutamine to account for disappearance of this magnitude of glutamic acid. In patient 1 approximately 5 per cent of the infused glutamate appeared in the urine as an increase in alpha amino nitrogen excretion.

The rise in ketoglutarate in eight of the ten cases seemed directly related to the infusion of glutamate (Figure 2). There are two principal routes by which glutamic acid can give rise to ketoglutarate (Figure 4 ), reaction No. 3 in which ammonia is released, and reaction No. 6 , the transamination reaction, in which one molecule of glutamic acid reacts with the keto-acids pyruvic or oxaloacetic to yield, respectively, alanine or aspartic acid and one molecule of ketoglutarate. The latter reaction does not produce ammonia.

The observations in Table IV show that alanine increases after sodium glutamate infusion. This amino acid was measured before and after sodium glutamate infusion in one additional normal person and in three patients in hepatic coma, and it consistently increased in all after the infusion. The details of these observations are reported in a subsequent paper (27). The loss of glutamic acid and the gain of alanine by the plasma suggest that transamination (No. 6, Figure 4) is occurring. Pyruvic acid would therefore be expected to disappear at the same time. This disappearance was not observed, but glucose was being infused rapidly (approximately $700 \mu \mathrm{M}$ per min.) in these patients and would serve to maintain the pyruvate level. The transamination reaction would also produce ketoglutarate. The ketoglutarate, once formed, may return to glutamic acid by reaction No. 4 and in this process would remove a molecule of free ammonia.

Walshe (7) presented data showing changes in ketoglutarate following glutamate infusions which are similar to these reported here, though he did not consider the rise in ketoglutarate significant. Pyruvic acid and citric acid levels were high in our study and thus confirm the observations that both are high in patients with liver disease $(22,28)$. However, the levels did not show consistent changes after the infusion of glutamate. Klingmüller and associates $(29,30)$ studied the disappearance of infused glutamic acid in rabbits.
They found that the level of serum glutamic acid returned to normal in two hours after the injection of $2 \mathrm{mM}$ per $\mathrm{kg}$. and it disappeared on a logarithmic curve. This is approximately the dose used in the present study. Klingmüller and his co-workers also found that ketoglutarate and alanine rose in the serum and in their animals the pyruvate level fell.

From these data we believe that glutamate lowers the blood ammonia by more than one mechanism: First, the combination of glutamic acid with ammonia to form glutamine, and second, the conversion of glutamic acid to ketoglutarate by transamination and the subsequent recombination of ketoglutarate with ammonia to form glutamic acid. This conclusion is based to a large degree on our inability to demonstrate a rise in glutamine comparable in each case to the fall in blood ammonia. The glutamine method employed, though not specific for glutamine, would be expected to produce results that are correct or erroneously high, but never erroneously low. The suggestion of Bessman (26) that the kidney was rapidly removing the glutamine by the formation of urinary ammonia was not investigated.

The biochemical changes observed following an infusion of glutamic acid were similar in the normal subjects and the patients with liver disease. Additional data on this point are presented elsewhere (27).

\section{SUMMARY}

Sodium glutamate was infused intravenously a total of 13 times in two normal subjects and eight patients with cirrhosis.

1. The blood "ammonia" levels fell in 11 of 12 , and the blood alpha-ketoglutarate levels rose in 8 of 10 instances, and the changes in blood pyruvate and citrate were variable.

2. Glutamine levels showed variable changes but did not rise sufficiently in all cases to account for the lowering of the blood "ammonia."

3. The pattern of response to the glutamic acid infusion was similar for normal subjects, patients with cirrhosis, and patients with hepatic coma, although the initial levels of these substances were elevated in the patients with cirrhosis.

4. Only one of seven patients in hepatic coma showed a suggestive clinical response to sodium glutamate infusion. 


\section{REFERENCES}

1. Adams, R. D., and Foley, J. M., The neurological disorder associated with liver disease. A. Research Nerv. \& Ment. Dis., Proc., 1953, 32, 198.

2. Phillips, G. B., Schwartz, R., Gabuzda, G. J., Jr., and Davidson, C. S., The syndrome of impending hepatic coma in patients with cirrhosis of the liver given certain nitrogenous substances. New England J. Med., 1952, 247, 239.

3. McDermott, W. V., Jr., and Adams, R. D., Episodic stupor associated with an Eck fistula in the human with particular reference to the metabolism of ammonia. J. Clin. Invest., 1954, 33, 1.

4. Kirk, E., Amino acid and ammonia metabolism in liver diseases. Acta med. Scandinav., 1936, Suppl. LXXVII, 1.

5. Bollman, J. L., and Mann, F. C., Studies on the physiology of the liver. XVII. The effect of removal of the liver on the formation of ammonia. Am. J. Physiol., 1930, 92, 92.

6. Walshe, J. M., The effect of glutamic acid on the coma of hepatic failure. Lancet, 1953, 1, 1075.

7. Walshe, J. M., Glutamic acid in hepatic coma. Lancet, 1955, 1, 1235.

8. Priest, W. M., Whitehead, T. P., and Whittaker, S. R. F., Effect of glutamic acid on the coma of hepatic failure. Lancet, 1953, 1, 1201.

9. Whitehead, T. P., Whittaker, S. R. F., and Prior, A. P., Hepatic coma. Lancet, 1954, 2, 43.

10. McDermott, W. V., Jr., Adams, R. D., and Riddell, A. G., Ammonia metabolism in man. Ann. Surg., 1954, 140, 539.

11. Walley, R. V., Treatment of hepatic coma with sodium glutamate. Lancet, 1954, 1, 157.

12. Singh, I. D., Barclay, J. A., and Cooke, W. T., Bloodammonia levels in relation to hepatic coma and the administration of glutamic acid. Lancet, 1954, 1, 1004.

13. Webster, L. T., Jr., and Davidson, C. S., The effect of sodium glutamate on hepatic coma. J. Clin. Invest., 1956, 35, 191.

14. Sherlock, S., Summerskill, W. H. J., White, L. P., and Phear, E. A., Portal-systemic encephalopathy: neurological complications of liver disease. Lancet, 1954, 2, 453.

15. Bessman, S. P., and Bessman, A. N., The cerebral and peripheral uptake of ammonia in liver disease with an hypothesis for the mechanism of hepatic coma. J. Clin. Invest., 1955, 34, 622.

16. Knowlton, M., Horner, W. H., Seligson, D., and Iber, F. L., Analytical procedures. Dept. of
Metabolism, Walter Reed Army Medical Center, U. S. Government Printing Office, 1955.

17. Seligson, D., and Seligson, H., A microdiffusion method for the determination of nitrogen liberated as ammonia. J. Lab. \& Clin. Med., 1951, 38, 324.

18. Mainland, D., Statistics in medical research in Methods in Medical Research, J. M. Steele, Ed. Chicago, Year Book Publishers, 1954, vol. 6, p. 121.

19. Bessman, S. P., and Bradley, J. E., Uptake of ammonia by muscle. Its implications in ammoniagenic coma. New England J. Med., 1955, 253, 1143.

20. Fisher, C. J., Faloon, W. W., Auchincloss, J. H., Eich, R., and Gilbert, R., Alteration in blood ammonia with changing oxygen concentrations. Gastroenterology, In press.

21. Iber, F. L., and Bruton, J., Glutamine and glutaminase in blood. Clin. Chem., 1956, 2, 413.

22. Seligson, D., McCormick, G. J., and Sborov, V., Blood ketoglutarate and pyruvate in liver disease. J. Clin. Invest., 1952, 31, 661.

23. Ettinger, R. H., Goldbaum, L. R., and Smith, L. H., Jr., A simplified photometric method for the determination of citric acid in biological fluids. J. Biol. Chem., 1952, 199, 531.

24. Moore, S., and Stein, W. H., Chromatography of amino acids on sulfonated polystyrene resins. J. Biol. Chem., 1951, 192, 663.

25. Foster, G. L., Schoenheimer, R., and Rittenberg, D., Studies in protein metabolism. V. The utilization of ammonia for amino acid and creatine formation in animals. J. Biol. Chem., 1939, 127, 319.

26. Bessman, S. P., Personal communication.

27. Iber, F. L., Rosen, H., Levenson, S. L., and Chalmers, T. C., The plasma amino acids in liver failure. J. Lab. \& Clin. Med., In press.

28. Smith, L. H., Jr., Ettinger, R. H., and Seligson, D., A comparison of the metabolism of fructose and glucose in hepatic disease and diabetes mellitus. J. Clin. Invest., 1953, 32, 273.

29. Klingmüller, V., and Vogelgesang, K. H., Untersuchungen über den Stoff wechsel der L(t)-Glutaminsäure. I. Allgemeinwirkungen und Veränderungen des Blutchemismus, insbesondere des $\mathrm{Ge}$ halts an Ketosäuren im Plasma nach Verabreichung von $L(+)$-Glutaminsäure in vivo. Ztschr. f. physiol. Chem., 1955, 300, 97.

30. Klingmüller, V., Gayer, J., and Bramstedt, F., Untersuchungen über den Stoffwechsel der L(t)-Glutaminsäure. II. Verschiebungen im Plasmaspiegel freier Aminosäuren nach Glutaminsäuregaben. Ztschr. f. physiol. Chem., 1955, 300, 107. 